\title{
United Electromagnetic Characteristics and Online Monitoring Method of Static Air-gap Eccentricity of Turbo-Generator
}

\author{
Gui-Ji Tang*, Meng-Qiang Ke*, Yu-Ling $\mathrm{He}^{\dagger}$ and Fa-Lin Wang*
}

\begin{abstract}
The purpose of this paper is to investigate the united Electromagnetic characteristics for the effective monitoring on the static air-gap eccentricity (SAGE) of turbo-generator. Different from other studies, this paper not only studies on the unbalanced magnetic pull (UMP) and the vibration characteristics of the stator and the rotor, but also investigates the harmonic features of the magnetic flux density and the circulating current inside the parallel branches (CCPB). The theoretical calculation, together with the finite-element-method (FEM) simulation and the experiment verification, is taken for a SDF-9 type non-salient generator. It is shown that, when SAGE occurs, apparent doublefrequency UMP and vibrations will be produced both on the stator and the rotor, while the CCPB will have an obvious increment at the $1^{\text {st }}$ harmonic component. In addition, the amplitude of the magnetic flux density will be of cosine distribution in the circumferential position of the air-gap, while in normal condition it is a constant. Moreover, the pass-band amplitude, together with the $1^{\text {st }}$ harmonic of the magnetic flux density, will be enlarged as well. These united electromagnetic characteristics can be used as the diagnosis and monitoring criterion for SAGE.
\end{abstract}

Keywords: Turbo-generator, SAGE, Magnetic flux density, UMP, Radial vibration, CCPB

\section{Introduction}

The air-gap between the stator and the rotor of generator is very hard to be strictly symmetry due to different factors such as the assembling error, the performing condition, the component wearing, etc. Researchers have given this kind of asymmetry a professional definition as air-gap eccentricity or rotor eccentricity [1-2]. Air-gap eccentricity widely exists in almost every generator and motor, and can be classified as three types [3-5], i.e., the static air-gap eccentricity (SAGE) whose minimum air-gap position is stable (such as the offset of the rotor), the dynamic airgap eccentricity whose minimum air-gap position will be changed as the rotor rotates (for example, the rotor is bending, or the rotor section is an ellipse), and the mixed air-gap eccentricity which is composed of the former two. The small air-gap eccentricity will not cause great influence to the generator set, while in the case of more than $10 \%$ eccentricity, it is treated as a mechanical fault [6] and needs to be fixed to protect the bearing and the winding from damage [6-7].

Commonly, the dynamic air-gap eccentricity is relatively small and not so easy to touch the threshold of $10 \%$ extent, while the other two kinds, which have the SAGE component, are much easier to get the threshold due to the failure of the bearing, the offset of the rotor, and the

$\dagger$ Corresponding Author: Dept. of Mechanical Engineering, North China Electric Power University, China. (heyuling1@163.com)

* Dept. of Mechanical Engineering, North China Electric Power University, China. (tanggjlk@ncepubd.edu.cn, \{kemengqiang, falinwang\} 163.com)

Received: May 20, 2015; Accepted: August 13, 2016 deformation of the stator core. For example, the stator core is suffering a magnetic pull at $2 f(f$ is the mechanical rotating frequency of the rotor, and for turbo-generators it is also the electrical frequency) [6-8] even in normal condition, and will gradually change to an ellipse section after a long period [9]. Then there is a SAGE being formed. Thus, it is significant to monitor SAGE online to keep it within the acceptable extent.

By far, researchers have obtained significant findings about the UMP and rotor vibration characteristics [7, 1011], the winding inductance change [12], the electromotive force and current features [13-14], and the magnetic field variation [15] under eccentricity faults, while the detailed harmonic characteristics of the magnetic flux density, stator vibrations, and CCPB are rarely taken into account. Recent monitoring methods for this kind of fault are mainly based on the detecting of these parameters [16-18]. However, the rotor vibration and the stator electromotive force are affected by many factors, and different failures may cause similar rotor vibration characteristics and stator current features. So in most cases, the rotor vibrationbased and the stator current-based methods are employed as a supplementary verification. Recently, scholars have also developed the detecting coil (flux probe) method to monitor this fault online [19]. The main thought of this method is to test the variation of the air-gap magnetic flux density. However, this method needs to fix extra coils on the inner surface of the stator core.

In fact, besides the commonly used parameters such as the rotor vibration and the stator voltages, the stator information and sometimes are even more effective to 
monitor and diagnose the faults [20-22]. The intent of this paper is to investigate the united Electromagnetic characteristics including the characteristics of UMP and the stator \& rotor vibrations, the harmonic properties of the magnetic flux density, and the features of CCPB at the same time, so that an effective monitoring method for SAGE can be developed.

\section{Theoretical Analysis}

\subsection{Magnetic flux density}

The magnetic flux density depends on two factors, one is the magnetomotive force, and the other is the permeance per unit area. SAGE mainly affects the permeance per unit area, while the magnetomotive force is generally the same as normal condition. More details about the magnetomotive force and the permeance per unit area are shown in Fig. 1, where $F_{s}$ and $F_{r}$ are the magnetomotive forces of the stator and the rotor, respectively, $F_{1}$ is the composite magnetomotive force composed of $F_{s}$ and $F_{r}, \psi$ is the internal power angle of the generator and is related to the load nature, $\beta$ is the angle between $F_{1}$ and $F_{r}, g$ is the radial air-gap length, $\alpha_{m}$ is the circumferential angle, and $\delta_{s}$ is the relatively SAGE.

The magnetic flux density can be obtained by multiplying the magnetomotive force by the permeance per unit area, and finally written as

$$
\left\{\begin{array}{l}
B_{N}\left(\alpha_{m}, t\right)=f\left(\alpha_{m}, t\right) \Lambda\left(\alpha_{m}, t\right)=F_{1} \cos \left(\omega t-\alpha_{m}-\beta\right) \frac{\mu_{0}}{g} \\
=F_{1} \Lambda_{0} \cos \left(\omega t-\alpha_{m}-\beta\right) \\
B_{F}\left(\alpha_{m}, \mathrm{t}\right)=f\left(\alpha_{m}, t\right) \Lambda\left(\alpha_{m}, t\right) \\
=F_{1} \cos \left(\omega t-\alpha_{m}-\beta\right) \frac{\mu_{0}}{g\left(1-\delta_{s} \cos \alpha_{m}\right)} \\
=F_{1}\left(\Lambda_{0}+0.5 \Lambda_{s}^{2}+\Lambda_{s} \cos \alpha_{m}\right. \\
\left.\quad+0.5 \Lambda_{s}^{2} \cos 2 \alpha_{m}\right) \cos \left(\omega t-\alpha_{m}-\beta\right)
\end{array}\right.
$$

where $B_{N}$ is the magnetic flux density in normal condition, $B_{F}$ is the magnetic flux density for SAGE, $\Lambda_{0}$ is the normal permeance per unit area, $\Lambda_{s}=\Lambda_{0} \delta_{s}$ is the permeance per unit area caused by SAGE. In Eq. (1), the faulty permeance per unit area is expanded by the power series, ignoring the higher harmonics whose order is more than 2 .

It can be seen in Eq. (1) that, the amplitude of the normal magnetic flux density is a constant, while under SAGE it is a circumferential position dependent variable. Moreover, it can be also found that at the minimum air-gap position where $\alpha_{m}=0$, the magnetic flux density amplitude will be increased as SAGE develops, while at the max airgap position where $\alpha_{m}=\pi$ the situation will be opposite. However, the general amplitude of the magnetic flux density under SAGE is larger than that of normal condition, because there is an extra DC component $0.5 \Lambda_{s}^{2}$ under

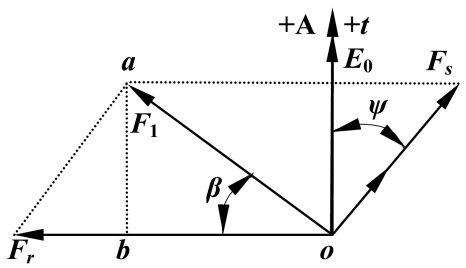

(a)

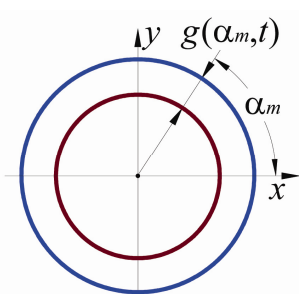

(b)

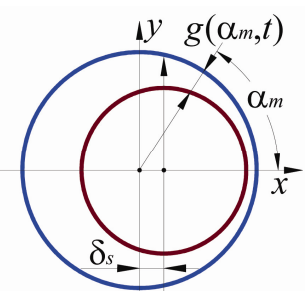

(c)
Fig. 1. Magnetomotive force and permeance per unit area of turbo-generator: (a) magnetomotive forces for normal condition and SAGE; (b) air-gap in normal condition whose permeance per unit area is $\Lambda_{0}=\mu_{0} / g$, and (c) air-gap under SAGE whose permeance per unit area is $\Lambda\left(\alpha_{m}\right)=\mu_{0} / g\left(1-\delta_{s} \cos \alpha_{m}\right)$

SAGE.

\subsection{Structure and excitation of stator and rotor}

\subsubsection{Stator structure and magnetic pull per unit area}

The stator of generator is composed of the stator core, the winding, the stator case, the end cap, etc., among which the stator core is the key component to afford the magnetic excitation force. The stator core consists of a lot of fanshaped steel sheets whose thickness size is $0.35 \mathrm{~mm}$ or $0.5 \mathrm{~mm}$, as indicated in Fig. 2 (a).

The whole inner surface of the stator core is loaded with the magnetic force, as shown in Fig. 2 (b). This force is actually like a surface pressure, and called magnetic pull per unit area (MPPUA). The integral of MPPUA to $\alpha_{m}$ is the final UMP. The radial vibration of the stator core can be treated as the periodic expanding and shrinking of the mass points. Mathematically, these periodic expanding and shrinking can be expressed as a displacement array of the mass points, whose kinetic equation is [23-24]

$$
M \ddot{x}(t)+C \dot{x}(t)+K x(t)=F(t)
$$

where $\boldsymbol{M}$ is the mass matrix of the stator core, $\boldsymbol{C}$ is the damping matrix, $\boldsymbol{K}$ is the stiffness matrix, $F(t)$ is the exciting load matrix, and $x(t)$ is the displacement response matrix of the structural mass points. Here the displacement response matrix is periodic and can be treated as the mathematical description of the radial vibration.

Physically, the stator core is a hollow shell and therefore its rigidity in the radial direction is relatively small. As 


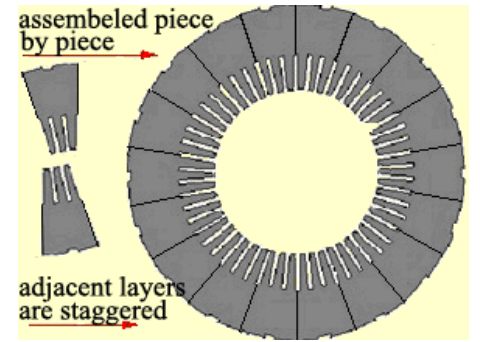

(a)

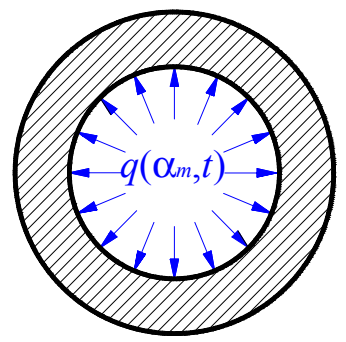

(b)
Fig. 2. Structure and magnetic force of stator core: (a) structure of stator core, and (b) MPPUA on stator core

indicated in Fig. 2 (b), even though the composite UMP is zero, under the action of the pulsating MPPUA $q\left(\alpha_{m}, t\right)$, the stator core will still have a periodic expanding and shrinking, i.e. the radial vibration. Thus, the significant excitation force of the stator core should be the MPPUA, not the composite UMP.

\subsubsection{Rotor structure and UMP}

The rotor is usually forged with a whole high-strength alloy which has good magnetic properties. Physically, it is a solid cylinder and therefore its radial stiffness is much larger than the stator. Though the outer surface of the rotor is also loaded with the pulsating MPPUA, this unit force is not enough to cause radial movements due to the rotor's large rigidity. However, the composite UMP will cause the rotor to have a periodical bending-returning movement in the radial direction, i.e. the radial vibration. Therefore, the significant exciting force for the rotor is the composite UMP.

\subsubsection{Exciting characteristics of MPPUA and UMP}

MPPUA formulas of stator in normal condition and SAGE cases are shown in Eq.(3), while the rotor UMP is indicated in Eq.(4). The subscript $N$ in the equations stands for normal condition, while $F$ stands for faulty conditions of SAGE.

$$
\left\{\begin{array}{l}
q_{N}\left(\alpha_{m}, t\right)=\frac{\left[B\left(\alpha_{m}, t\right)\right]^{2}}{2 \mu_{0}} \\
=\frac{F_{1}^{2}}{8 \mu_{0}}\left[2 \Lambda_{0}^{2}+2 \Lambda_{0}^{2} \cos \left(2 \omega t-2 \alpha_{m}-2 \beta\right)\right] \\
q_{F}\left(\alpha_{m}, t\right)=\frac{\left[B\left(\alpha_{m}, t\right)\right]^{2}}{2 \mu_{0}} \\
=\frac{F_{1}^{2}}{8 \mu_{0}}\left\{\left[\left(2 \Lambda_{0}^{2}+\Lambda_{s}^{2}\right)+\left(4 \Lambda_{0} \Lambda_{s} \cos \alpha_{m}\right)+\left(\Lambda_{s}^{2} \cos 2 \alpha_{m}\right)\right]\right. \\
\quad+\left[0.5 \Lambda_{s}^{2} \cos (2 \omega t-2 \beta)+2 \Lambda_{0} \Lambda_{s} \cos \left(2 \omega t-\alpha_{m}-2 \beta\right)\right. \\
\quad+\left(2 \Lambda_{0}^{2}+\Lambda_{s}^{2}\right) \cos \left(2 \omega t-2 \alpha_{m}-2 \beta\right) \\
\quad+2 \Lambda_{0} \Lambda_{s} \cos \left(2 \omega t-3 \alpha_{m}-2 \beta\right) \\
\left.\left.\quad+0.5 \Lambda_{s}^{2} \cos \left(2 \omega t-4 \alpha_{m}-2 \beta\right)\right]\right\}
\end{array}\right.
$$

$$
\left\{\begin{array}{l}
\left\{\begin{array}{l}
F_{N X}=L R \int_{0}^{2 \pi} q\left(\alpha_{m}, t\right) \cos \alpha_{m} d \alpha_{m}=0 \\
F_{N Y}=L R \int_{0}^{2 \pi} q\left(\alpha_{m}, t\right) \sin \alpha_{m} d \alpha_{m}=0
\end{array}\right. \\
\left\{\begin{array}{l}
F_{F X}=\frac{L R F_{1}^{2} \pi}{4 \mu_{0}}\left[2 \Lambda_{0} \Lambda_{s}+\Lambda_{0} \Lambda_{s} \cos (2 \omega t-2 \beta)\right] \\
F_{F Y}=\frac{L R F_{1}^{2} \pi}{4 \mu_{0}}\left[\Lambda_{0} \Lambda_{s} \sin (2 \omega t-2 \beta)\right]
\end{array}\right.
\end{array}\right.
$$

As indicated in Eq. (3), normally, the stator affords a constant force and a pulsating force at $2 f$, of which the constant one will not generate vibrations but only induce a radial deformation tendency to the stator core after a long period, while the pulsating one will cause radial vibrations at the same frequency as the force. When SAGE occurs, both the constant force and the pulsating force will be enlarged. Consequently, the deformation tendency and the radial vibration will be intensified.

Similarly, according to Eq. (4), the rotor will have no vibrations in theory under normal condition, while under SAGE it will vibrate at $2 f$ and meanwhile have a bending tendency in $\mathrm{X}$ direction.

Since the factor $\Lambda_{s}$, which stands for the permeance per unit area caused by SAGE, exists in the formulas of MPPUA and UMP, it is easy to deduce that, the development of SAGE will intensify the vibration amplitude and the radial deformation tendency of the stator and the rotor.

\subsection{CCPB analysis}

The CCPB, which is a kind of unbalanced current and depends on the electromotive force difference between the two adjacent parallel branches, will be induced and have various harmonic characteristics due to different failures. Taking Phase A of the SDF-9 type fault simulating generator as an example, since the circumferential distance between the corresponding coils of the two branches is 180 degree (see Fig. 3 (a)), the electromotive forces for these two branches before and after SAGE are [21-22]

$$
\left\{\begin{array}{c}
E_{a 1}\left(\alpha_{m}, t\right)=\left\{\begin{array}{c}
2 q w_{c} k_{w 1} \tau l f F_{1} \Lambda_{0} \cos \left(\omega t-\alpha_{m}-\beta\right) \cdots \cdots \cdots \cdots(\text { normal }) \\
2 q w_{c} k_{w 1} \tau l f F_{1}\left(\Lambda_{0}+0.5 \Lambda_{s}^{2}+\Lambda_{s} \cos \alpha_{m} \ldots \ldots .(\mathrm{SAGE})\right. \\
\left.+0.5 \Lambda_{s}^{2} \cos 2 \alpha_{m}\right) \cos \left(\omega t-\alpha_{m}-\beta\right)
\end{array}\right. \\
E_{a 2}\left(\alpha_{m}, t\right)=\left\{\begin{array}{c}
2 q w_{c} k_{w 1} \tau l f F_{1} \Lambda_{0} \cos \left(\omega t-\alpha_{m}-\pi-\beta\right) \cdots \cdots(\text { normal }) \\
2 q w_{c} k_{w 1} \tau l f F_{1}\left[\Lambda_{0}+0.5 \Lambda_{s}^{2}+\Lambda_{s} \cos \left(\alpha_{m}+\pi\right)\right. \\
\left.+0.5 \Lambda_{s}^{2} \cos 2\left(\alpha_{m}+\pi\right)\right] \cos \left(\omega t-\alpha_{m}-\pi-\beta\right)
\end{array}\right. \text { (SAGE) }
\end{array}\right.
$$

where $E_{a 1}$ and $E_{a 2}$ are the electromotive forces of the two branches, respectively, $q$ is the number of slots for each pole per phase, $w_{c}$ is the number of turns for each branch winding, $k_{w 1}$ is the fundamental frequency winding factor, $\tau$ 
is the polar distance, $l$ is the effective length of the winding, and $f$ is the electrical frequency.

The electromotive force difference between the two branches indicated in Fig. 3 (b) can be obtained via [21-22]

$$
\begin{aligned}
U_{a 12}\left(\alpha_{m}, t\right)= & -E_{a 1}\left(\alpha_{m}, t\right)+j \omega L_{a 1} I_{a 1}+R_{a 1} I_{a 1}+j \omega \sum_{i} M_{a 1 i} I_{i} \\
& -j \omega \sum_{k} M_{a 2 k} I_{k}-R_{a 2} I_{a 2}-j \omega L_{a 2} I_{a 2}-E_{a 2}\left(\alpha_{m}, t\right)
\end{aligned}
$$

Feed Eq. (5) into (6), the electromotive force differences

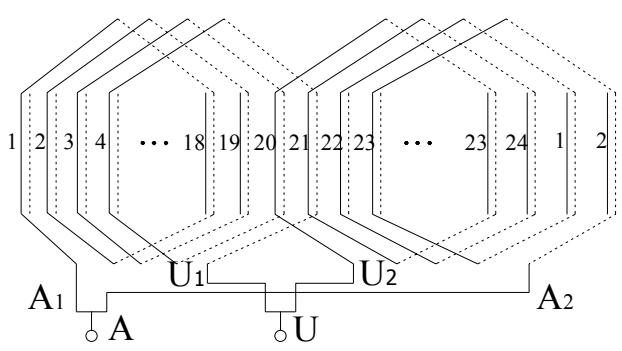

(a)

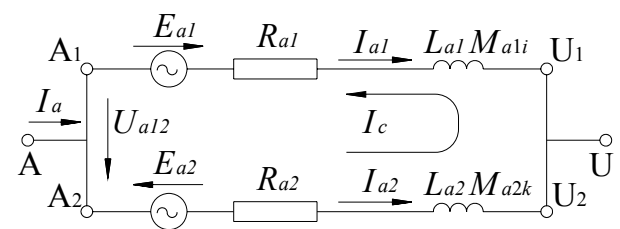

(b)

Fig. 3. Electromotive force difference and CCPB: (a) winding distribution of Phase $\mathrm{A}$, and (b) equal circuit of parallel branches of Phase A

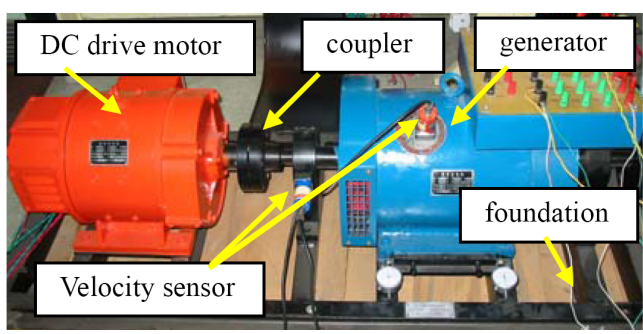

(a)

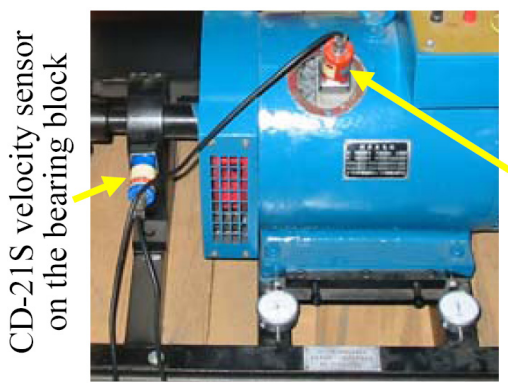

(c)

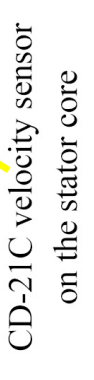

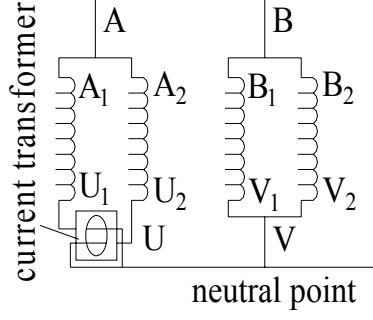

(d) before and after SAGE are

$U_{a 12}=\left\{\begin{array}{l}0 \ldots \ldots \ldots \ldots \ldots \ldots \ldots \ldots \ldots \ldots \ldots \ldots \ldots \ldots \ldots \ldots \\ -4 q w_{c} k_{w 1} \\ l f f F_{1} \Lambda_{s} \cos \alpha_{m} \cos \left(\omega t-\alpha_{m}-\beta\right) \cdot(\mathrm{SAGE})\end{array}\right.$

As indicated in Eq. (7), theoretically, there is no CCPB in normal condition, while under SAGE, the $1^{\text {st }}$ harmonic CCPB will be induced. Moreover, as SAGE is increased, the amplitude of CCPB will also be enlarged.

\section{Calculation and Experiment Study}

\subsection{Object and methods}

The calculation study, which includes the theoretical

Table 1. Primary parameters of study object

\begin{tabular}{c|c}
\hline Parameters & Values \\
\hline rated capacity & $7.5 \mathrm{kVA}$ \\
\hline rated exciting current & $1.5 \mathrm{~A}$ \\
\hline rated rotation speed & $3000 \mathrm{r} / \mathrm{min}$ \\
\hline number of pole pairs & $p=1$ \\
\hline polar distance & $\tau=252 \mathrm{~mm}$ \\
\hline radial air-gap length & $g=0.8 \mathrm{~mm}$ \\
\hline number of exciting slots per pole & 6 \\
\hline number of exciting turns peer pole & 480 \\
\hline number of stator slots & 24 \\
\hline number of turns in series per phase & 100 \\
\hline ratio of pitch to polar distance & $k_{y}=y / \tau=0.83$ \\
\hline pitch shortening factor & $k_{p}=0.966$ \\
\hline
\end{tabular}

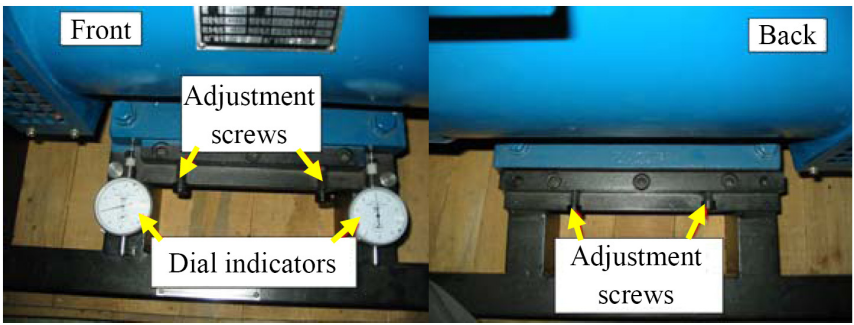

(b)

Fig. 4. Experiment method of the fault simulating generator: (a) general outlook; (b) method to set SAGE; (c) method to set vibration sensors; (d) method to test CCPB, and (e) testing system of the experiment 
calculation with MATLAB and the FEM simulation with Ansoft Maxwell, is taken together with the experiment study on the object of SDF-9 type fault simulating generator in the National Key Lab of New Energy and Electrical Engineering, P.R. China, as indicated in Fig. 4 (a). The primary parameters of the generator are shown in Table 1.

The rotor of the generator is kept to the underframe by the bearing pedestal, while the stator can be moved along the horizontally radial direction by adjusting the four screws, see Fig. 4 (b). The movement can be controlled by two dial indicators, so that different faulty degrees of SAGE can be simulated.

During the experiment, two velocity sensors are employed to test the stator vibration and the rotor vibration (see Fig. 4 (a) and (c)), while the CCPB is measured by a current transformer (see Fig. 4 (d), the conductors of the two branches inversely cross the current transformer to get the current difference which is also the CCPB). The tested

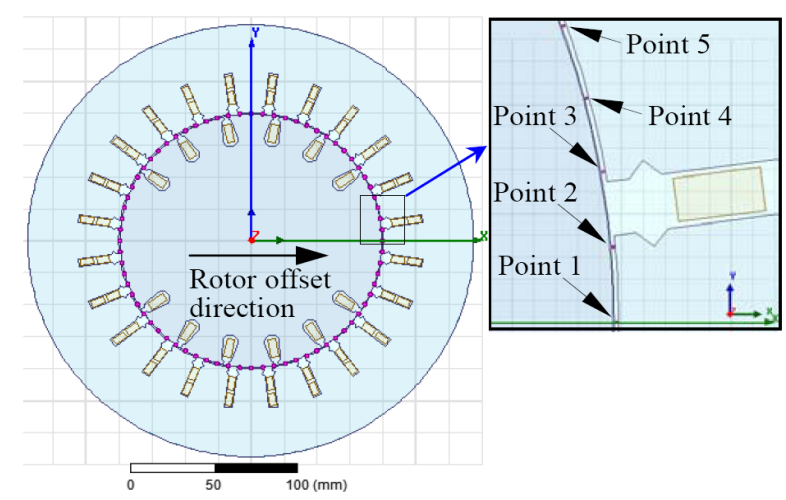

(a) data is collected by a U60116C type collector and stored in the computer, see Fig. 4 (e).

The theoretical calculation is based on the deduced formulas in the theory analysis section. The fault simulating generator is specifically designed ourselves. And we have the detailed mechanical and electrical parameters. We feed these parameters into the corresponding theoretical equations and calculate them with MATLAB to obtain the theoretical results.

The FEM simulating model for different SAGE cases is established by shifting the rotor and the field windings along $\mathrm{X}$-axis with $0 \mathrm{~mm}$ (normal condition), $0.1 \mathrm{~mm}, 0.2 \mathrm{~mm}$, and $0.3 \mathrm{~mm}$, respectively (see Fig. 5(a)). The same eccentricity values are also set in the experiment. During the simulation, the excitation is loaded by means of using a DC current source through the coupling circuit of the field windings, see Fig. 5 (b). And the coupling circuit for the stator windings is indicated in Fig. 5 (c).

During the simulation and the experiment, the rotation speed of the rotor is set to 3000rpm, the exciting current is set to $0.8 \mathrm{~A}$, the sampling frequency is set to $10 \mathrm{k} \mathrm{Hz}$, and the output line voltage is $380 \mathrm{~V}$.

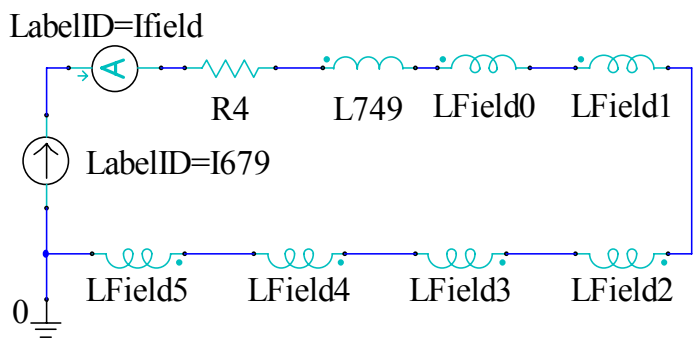

(b)

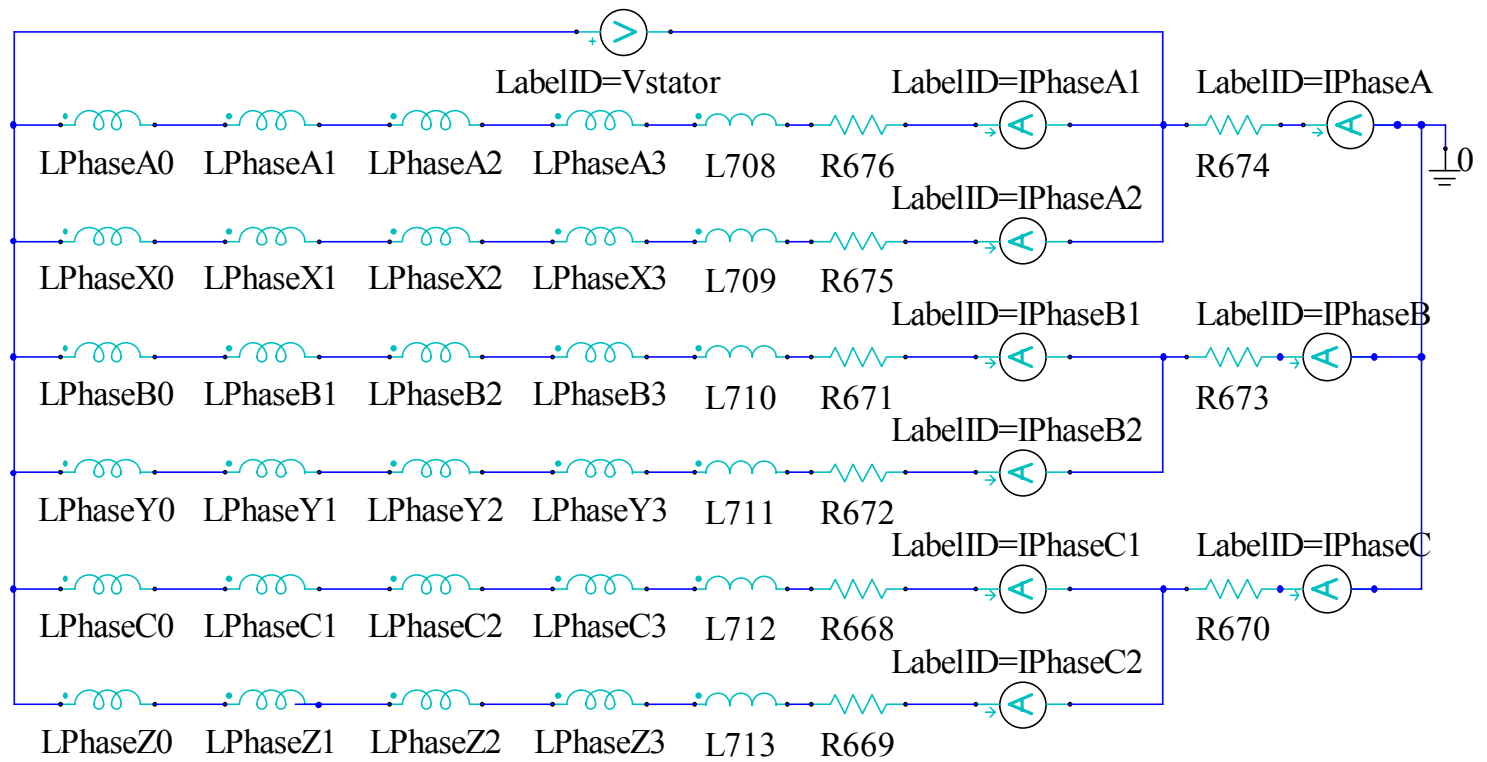

(c)

Fig. 5. Simulating model of the generator: (a) simulating model and magnetic flux density sampling point set, (b) coupling circuit for exciting winding, and (c) coupling circuit for stator winding 


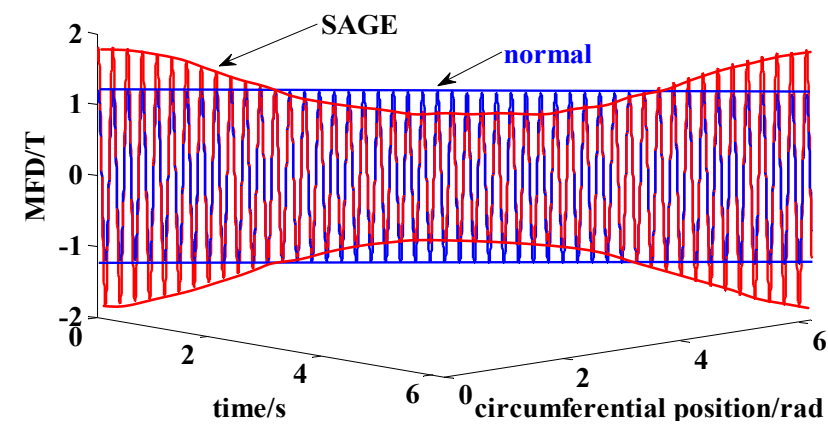

(a)

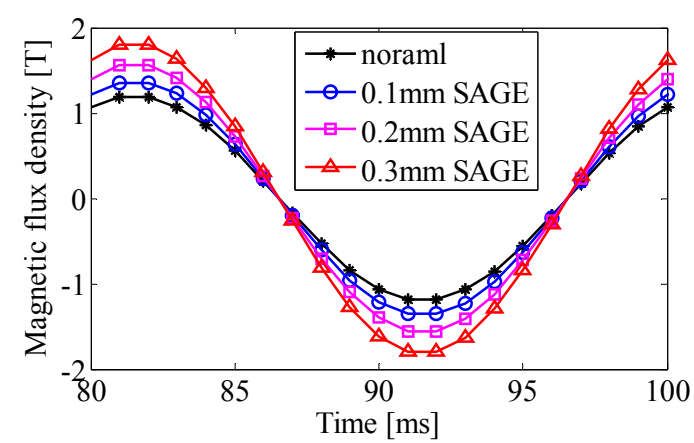

(c)

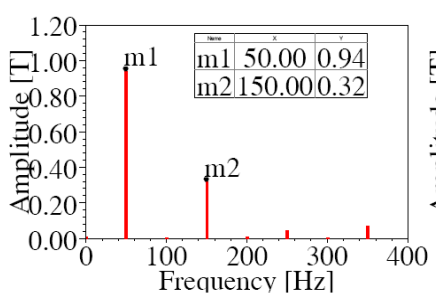

(e)

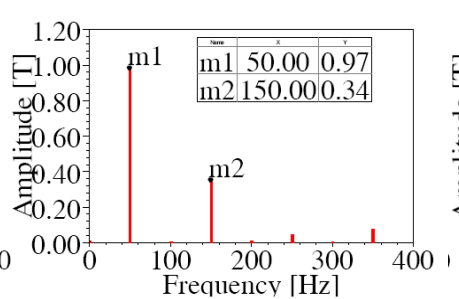

(f)

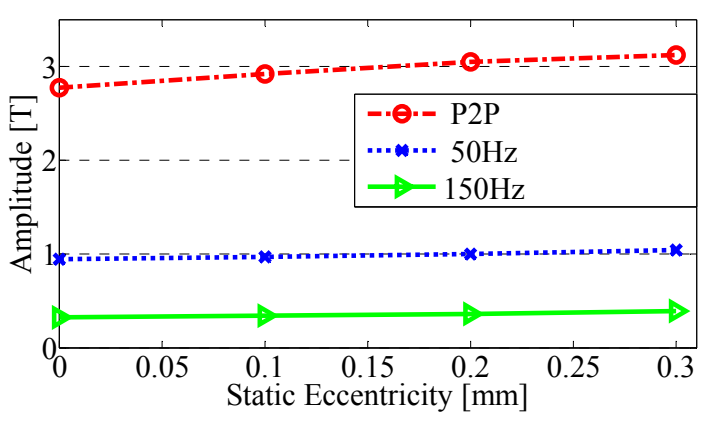

(b)

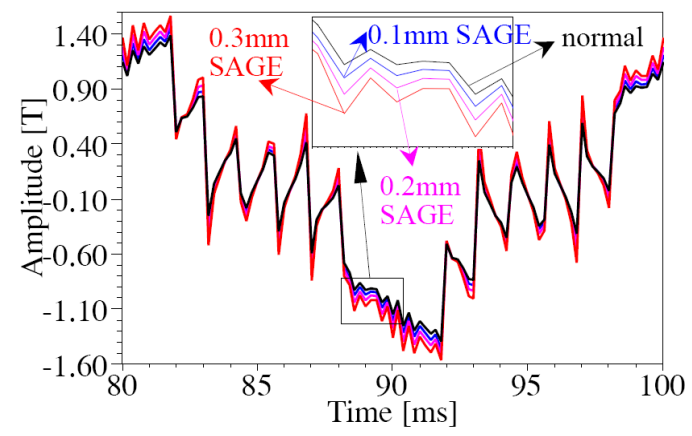

(d)

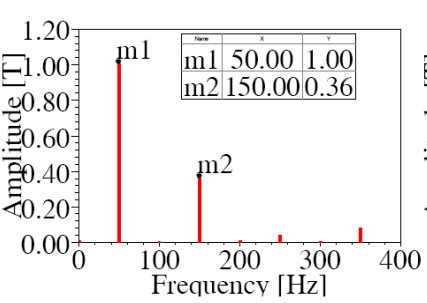

(g)

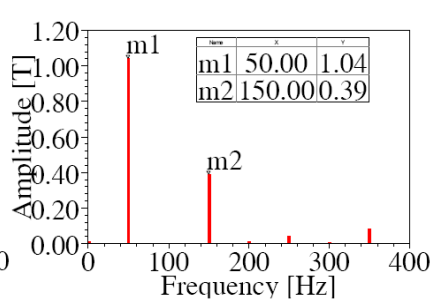

(h)

Fig. 6. Magnetic flux density results: (a) theoretical 3D curves; (b) statistic root-mean-square values of the 72 sampling points in the simulation; (c) and (d) theoretical and simulating results of magnetic flux density at the minimum airgap position, and (e)-(h) simulating spectra under normal condition, $0.1 \mathrm{~mm}$ SAGE, 0.2 $\mathrm{mm}$ SAGE, and $0.3 \mathrm{~mm}$ SAGE, respectively

\subsection{Results and discussion}

\subsubsection{Influence on magnetic flux densit}

The magnetic flux density result is only obtained by the theoretical calculation and the FEM simulation, while it is not sampled during the experiment due to the condition limitations (Usually the magnetic flux density measurement is based on the search coil or Hall sensor fixed inside the generator. However, the air-gap of the fault simulating generator is very small and it is hard to fix such a search coil. It is also difficult to install the Hall sensor due to the stator envelope).

Since the magnetic flux density under SAGE is a circumferential position dependent function, to get the overall pass-band value and the detailed partial information at the same time, 72 sampling points are equidistantly set on a circle of the air-gap to compute the root-mean-square values during simulation, see Fig. 5 (a).

The magnetic flux density result of the whole solution domain is shown in Fig. 6 (a) and (b), while the partial information at the minimum air-gap position is indicated in (c) to (h). As indicated in Fig. 6 (a), when SAGE occurs, the amplitude of the air-gap magnetic flux density will be of cosine distribution, while in normal condition the amplitude is a constant. This is in agreement with the previous analysis (see Fig. 1 (c) and Eq. (1)). Moreover, as SAGE develops, the magnetic flux density amplitudes, including the peak-to-peak (p2p) value, and the $1^{\text {st }}$ and the $3^{\text {rd }}$ harmonic amplitudes, will be increased, see Fig. 6 (b).

Previously, the theoretical analysis shows that SAGE will mainly cause the $1^{\text {st }}$ harmonic amplitude and the passband amplitude of the magnetic flux density to be enlarged, while actually in the simulation the $3^{\text {rd }}$ harmonic amplitude is also increased. This is because that the higher order harmonics whose order is more than 2 are ignored during 


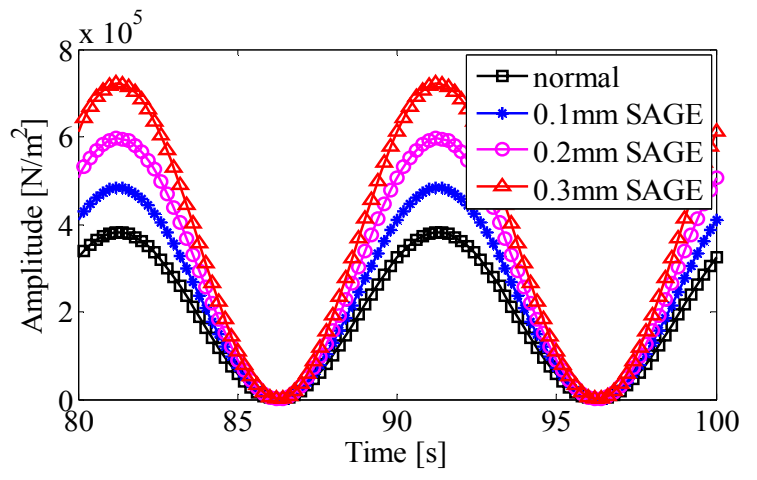

(a)

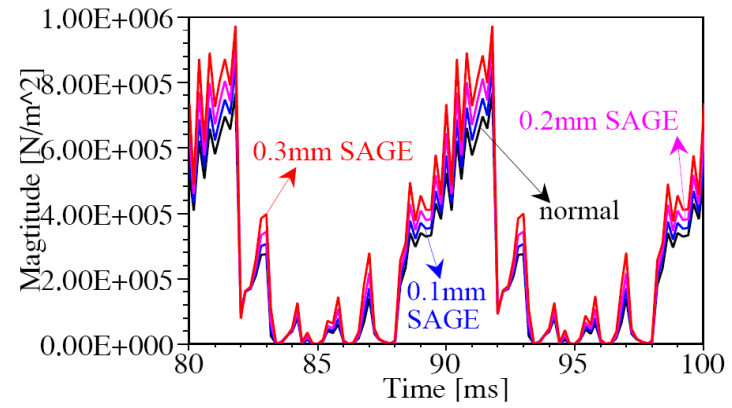

(b)

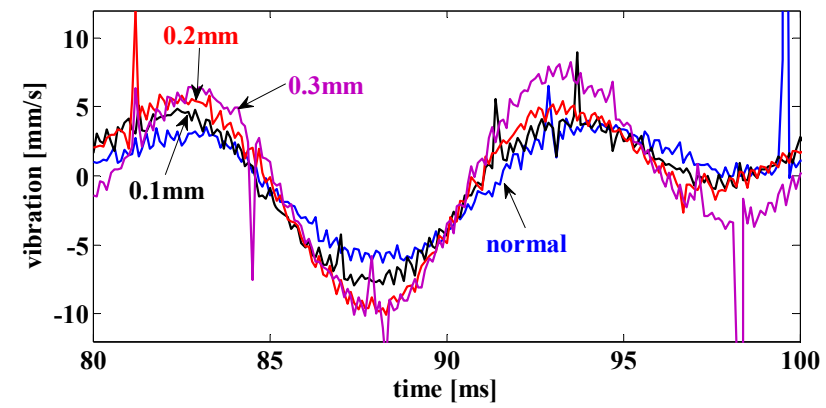

(c)

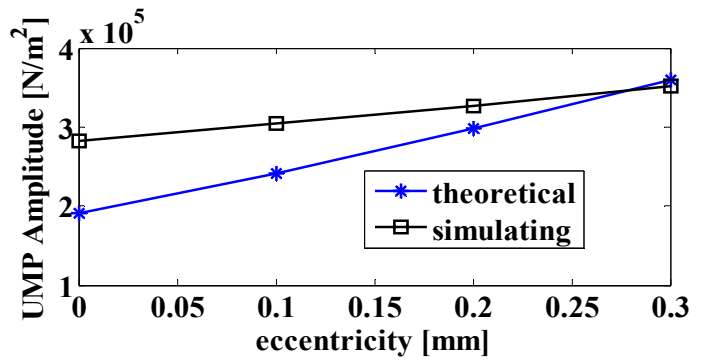

(d)

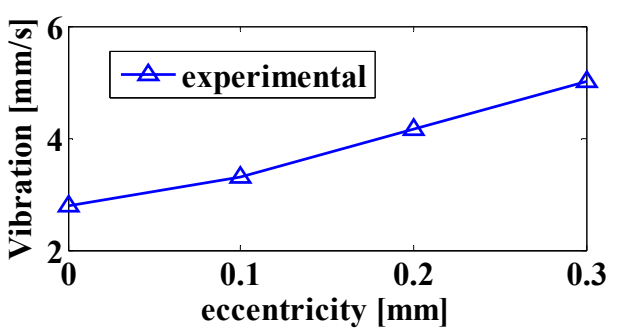

(e)

Fig. 7. Curves of MPPUA and vibration of stator: (a) theoretical MPPUA; (b) simulating MPPUA; (c) tested stator vibration velocity; (d) comparison of the $2^{\text {nd }}$ harmonic MPPUA, and (e) tested $2^{\text {nd }}$ harmonic vibration component

Table 2. Magnetic flux density amplitudes at the minimum air-gap position

\begin{tabular}{c|c|c|c}
\hline \multirow{2}{*}{ Running condition } & \multicolumn{3}{|c}{ Magnetic flux density amplitude (T) } \\
\cline { 2 - 4 } & $\mathrm{p} 2 \mathrm{p}$ & $50 \mathrm{~Hz}$ & $150 \mathrm{~Hz}$ \\
\hline normal & 2.77 & 0.94 & 0.32 \\
\hline $0.1 \mathrm{~mm}$ SAGE & 2.92 & 0.97 & 0.34 \\
\hline $0.2 \mathrm{~mm}$ SAGE & 3.05 & 1.00 & 0.36 \\
\hline $0.3 \mathrm{~mm}$ SAGE & 3.12 & 1.04 & 0.39 \\
\hline
\end{tabular}

the previous analysis, while in fact there is each odd harmonic exiting.

The partial information shows that, the developing tendency of the magnetic flux density at the minimum airgap position is generally the same as that of the statistic root-mean-square values of all the 72 sampling points, as indicated in Fig. 6 (b) to (h). However, in theory, as shown in Fig. 6 (a), the growing trend of the magnetic flux density at the max air-gap position will be opposite to that at the minimum air-gap position. Due to the space limitation of the paper, the detailed data about the magnetic flux density at the max air-gap position is not given. More details about the amplitudes at the minimum air-gap position can be found in Table 2. Generally, the theoretical result is consistent with the simulating one.

\subsubsection{Influence on stator MPPUA and vibration}

Theoretical and simulating MPPUAs under normal condition and different SAGE situations are shown in Fig. 7 (a) and (b), respectively, while the tested vibration curves obtained from the SDF-9 type fault simulating generator are indicated in Fig. 7 (c). Technically, the transient curves of the former $80 \mathrm{~ms}$ are cut off because the experiment system begins to be steady at about $65 \mathrm{~ms}$. Obviously, the period of the MPPUA and the vibration is $10 \mathrm{~ms}$, which means that the pulsating frequency is $100 \mathrm{~Hz}$. In addition, the MPPUA and the vibration amplitudes will both be enlarged when SAGE occurs. And, as SAGE is increased, 

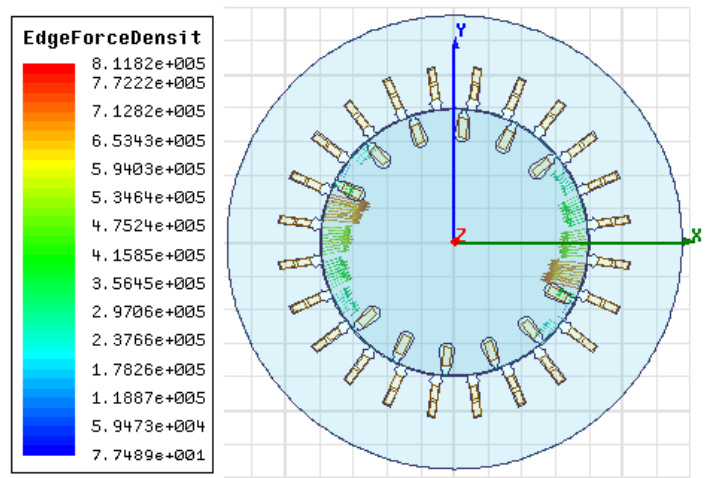

(a)

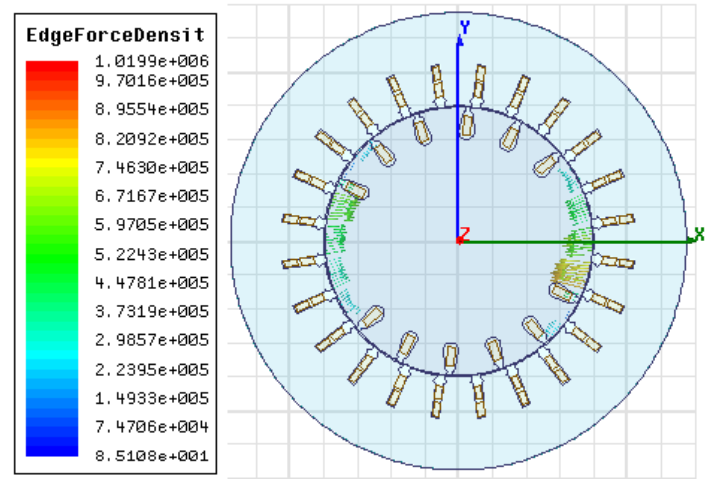

(c)
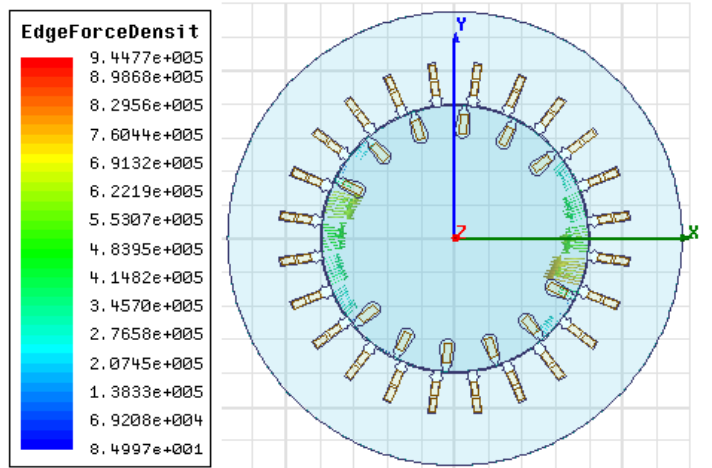

(b)
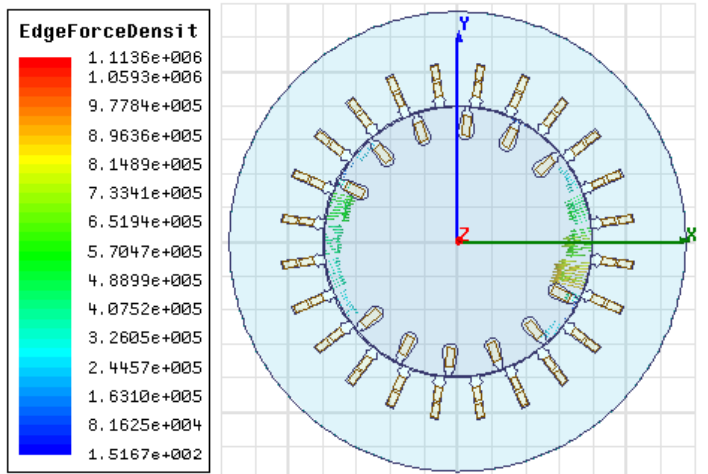

(d)

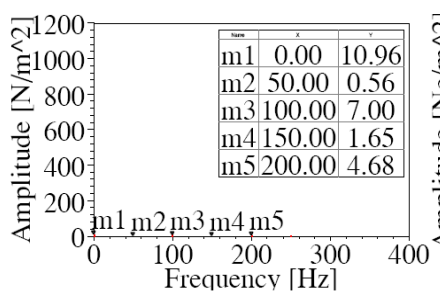

(e)

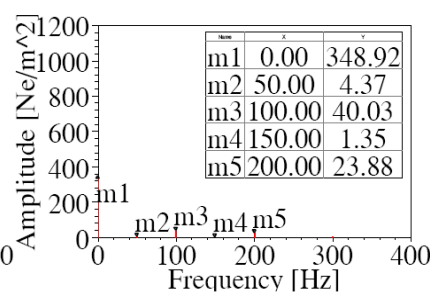

(f)

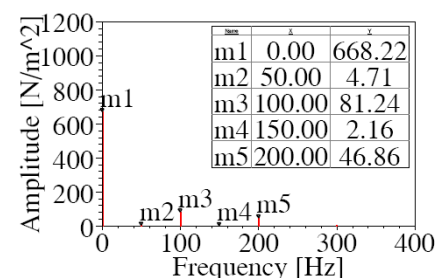

(g)

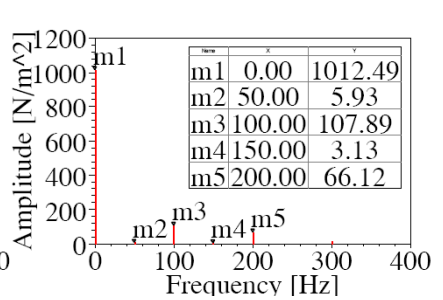

(h)

Fig. 8. Vector diagram and spectra of the simulating MPPUA: (a)-(d) vector diagrams in the case of normal condition, $0.1 \mathrm{~mm}$ SAGE, 0.2mm SAGE, and 0.3mm SAGE, respectively, and (e)-(h) MPPUA spectra in the case of normal condition, $0.1 \mathrm{~mm}$ SAGE, $0.2 \mathrm{~mm}$ SAGE, and $0.3 \mathrm{~mm}$ SAGE, respectively

the MPPUA and the vibrations will be also intensified. The growing tendency of the simulating MPPUA and the stator vibration is in accordance with that of the theoretical curves. These results match the previous analysis well.

Comparisons among the theoretical MPPUA, the simulating MPPUA, and the tested vibration amplitude at $100 \mathrm{~Hz}$, are shown in Fig. 7 (d) and (e). It is indicated that, the $2^{\text {nd }}$ harmonic vibration components will be increased as SAGE develops, and its growing trend follows the tendency of the MPPUA.

To show more detailed information, the simulating MPPUA spectra and the vector diagrams are presented in Fig.8. It is indicated that the MPPUA will obtain the max value around the magnetic poles in normal condition, and the max value along the eccentricity direction under SAGE (the SAGE is generally along the $\mathrm{X}$ axis, see Fig. 5 (a)).
Moreover, in the case of SAGE, the $\mathrm{p} 2 \mathrm{p}$ values, together with the mean values $(0 \mathrm{~Hz})$ and the $2^{\text {nd }}$ harmonic values will have an apparent increment. The increasing rate of the $\mathrm{p} 2 \mathrm{p}$ values from normal condition to $0.1,0.2$, and $0.3 \mathrm{~mm}$ SAGE cases are $273.25 \%, 651.02 \%$, and $969.76 \%$, respectively, while the rise rates of the mean values are $3083.58 \%$, 5996.90\%, and $9138.05 \%$, respectively, and the relatively increments of the $2^{\text {nd }}$ harmonic values are $471.86 \%, 1060.57 \%$, and $1441.29 \%$, respectively. This phenomenon follows the previous theoretical results.

\subsubsection{Influence on rotor UMP and vibration}

The theoretical and the simulating rotor UMPs in $\mathrm{X}$ direction and $\mathrm{Y}$ direction are indicated in Fig. 9 (a)-(d), while the tested vibration curves of the rotor in $\mathrm{X}$ direction 


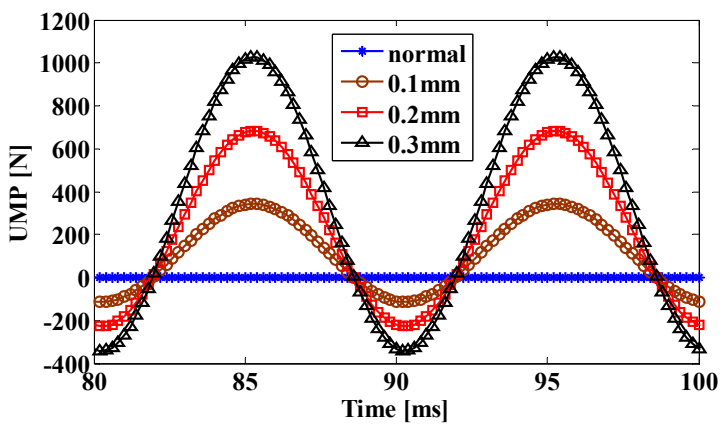

(a)

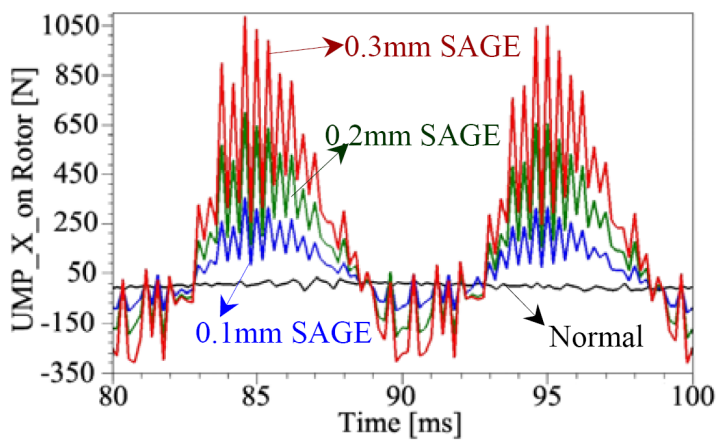

(c)

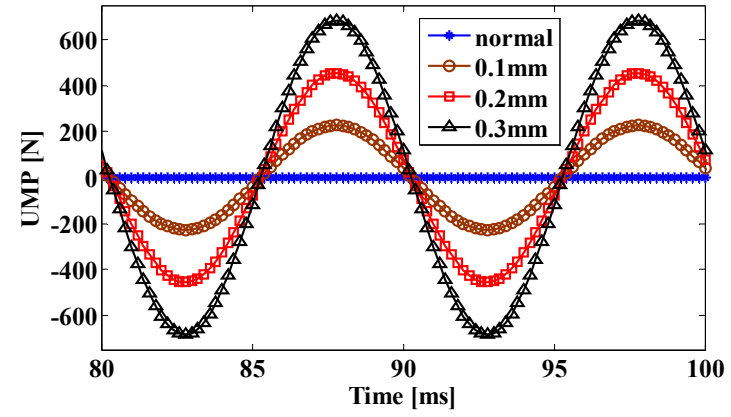

(b)

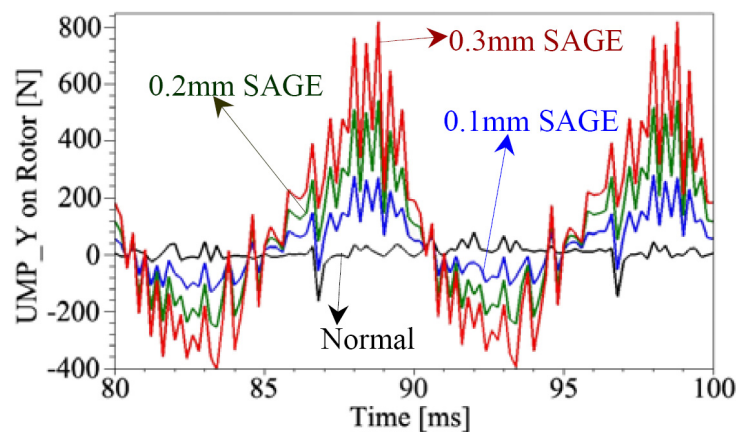

(d)

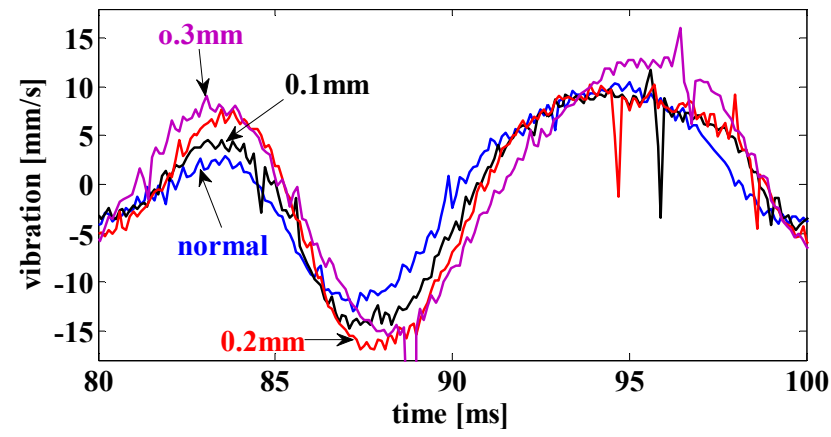

(e)

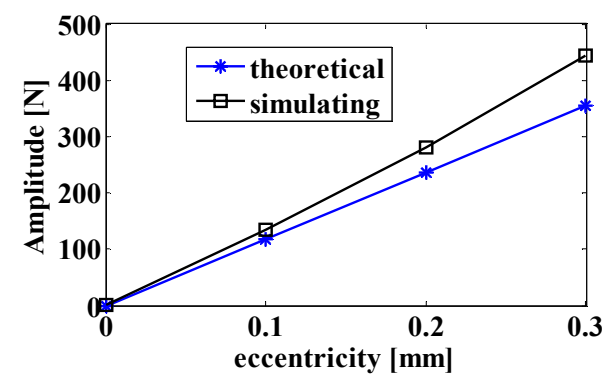

(f)

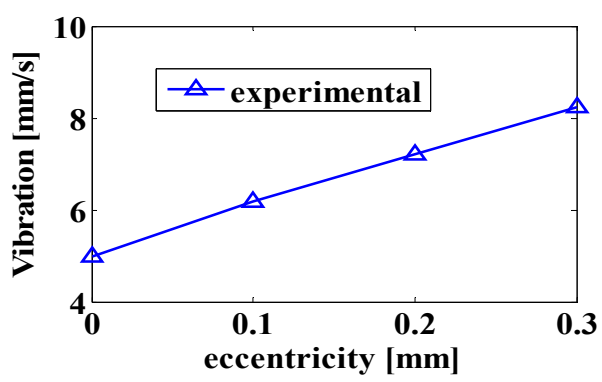

$(\mathrm{g})$

Fig. 9. Curves of UMP and vibration of rotor: (a) and (b) theoretical UMP in X direction and Y direction, respectively, while (c) and (d) simulating UMP in X direction and Y direction, respectively, (e) tested vibration in X direction, (f) the $2^{\text {nd }}$ harmonic UMP comparison in $\mathrm{X}$ direction, and $(\mathrm{g})$ tested $2^{\text {nd }}$ harmonic vibration in $\mathrm{X}$ direction

is shown in Fig. 9 (e). It is shown that, the occurrence of SAGE will cause apparent UMPs in both $\mathrm{X}$ direction and $\mathrm{Y}$ direction, and also the radial rotor vibrations. Moreover, as SAGE increases, the UMPS and the vibrations will also be increased. Though there are value differences existing between the theoretical and the simulating curves, the general tendency of the UMPs and the vibrations matches very well with each other, showing that the simulating and the experimental results are in consistent with the theoretical one. 

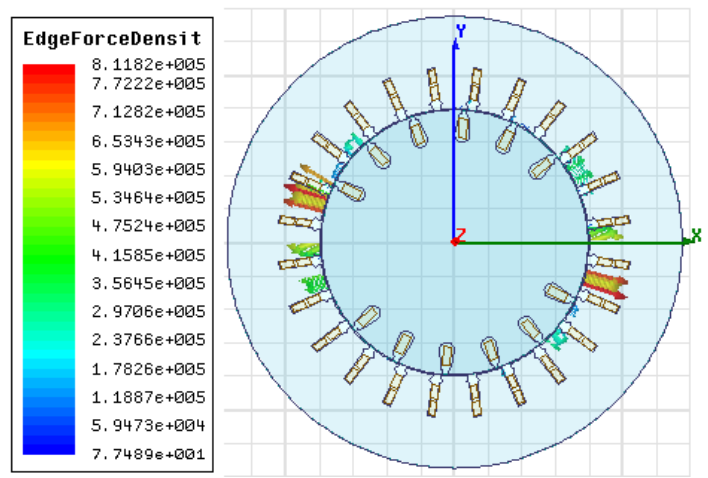

(a)

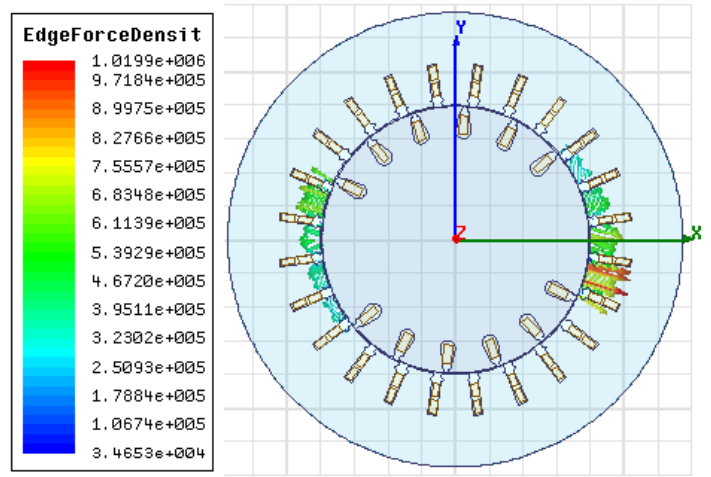

(c)
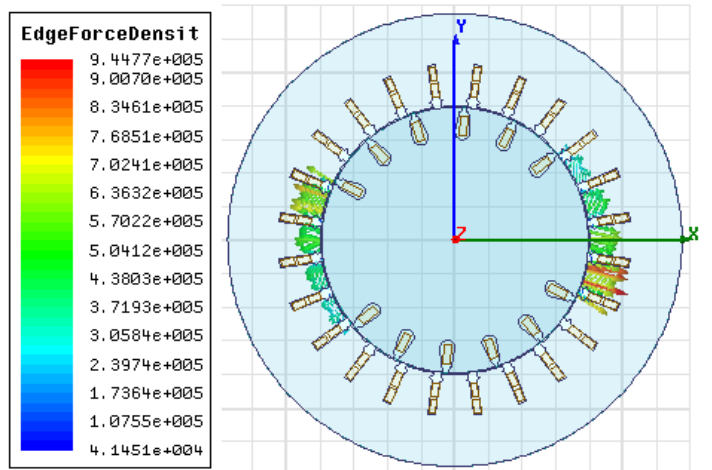

(b)
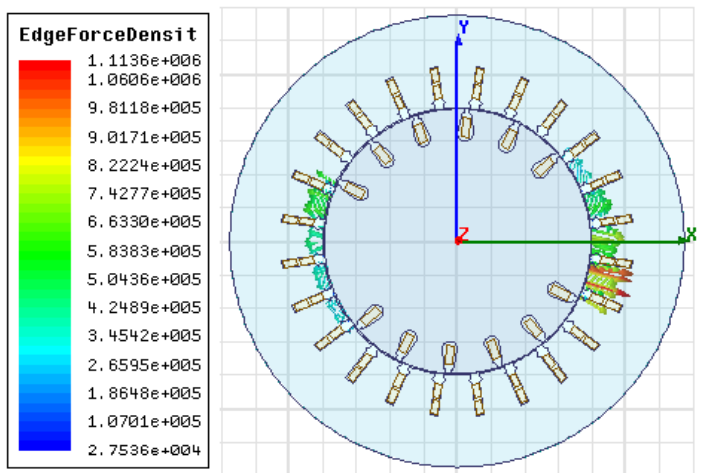

(d)

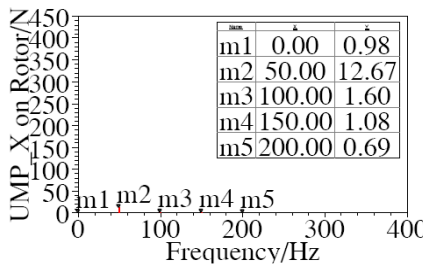

(e)

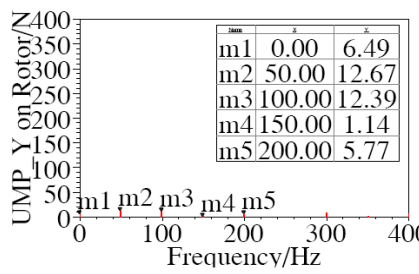

(i)

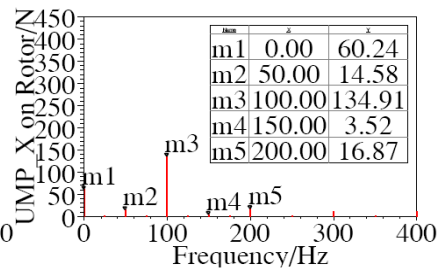

(f)

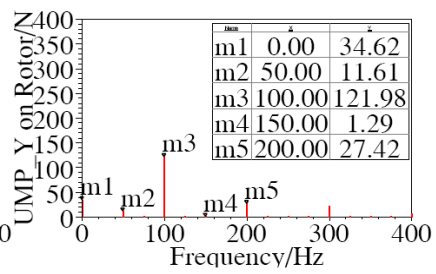

(j)

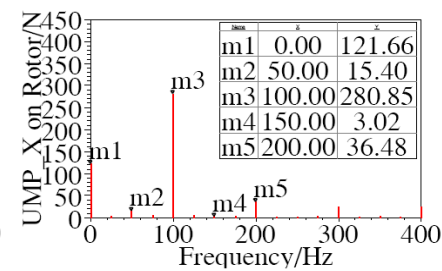

(g)

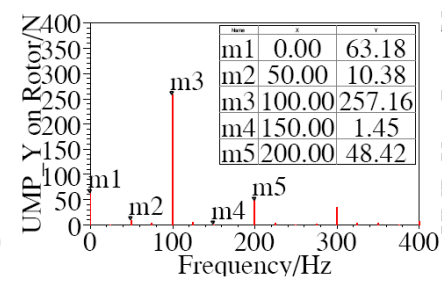

(k)

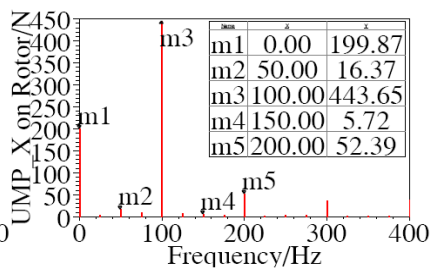

(h)

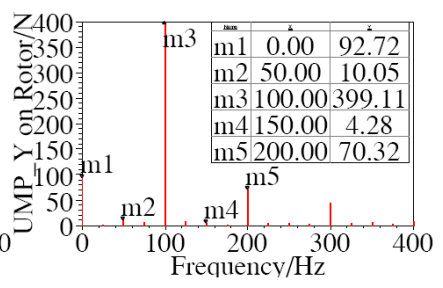

(1)

Fig. 10. Simulating vector diagram and spectra of rotor UMP: (a)-(d) vector diagrams, (e)-(h) UMP spectrum of X direction, and (i)-(1) UMP spectrum of $Y$ direction in the case of normal condition, $0.1 \mathrm{~mm}$ SAGE, 0.2mm SAGE, and $0.3 \mathrm{~mm}$ SAGE, respectively

The comparisons of the key characteristic component which people are usually interested in, i.e., the $2^{\text {nd }}$ harmonic, are presented in Fig. 9 (f) and (g), indicating a good agreement between the calculation study and the experimental testing. More detailed information about the UMP is presented in Fig. 10. It shows that the magnetic pull in normal condition is of symmetric distribution, while under SAGE the magnetic pull on the right side (also the eccentricity direction) is obviously larger than that on the left side. In addition, as SAGE increases, the D-values of the magnetic pull on the two sides, i.e., the UMP, will be also enlarged.

The growing tendencies of the UMP in $\mathrm{X}$ direction and $\mathrm{Y}$ direction indicated in Fig. 10 (e)-(1), are very similar to 


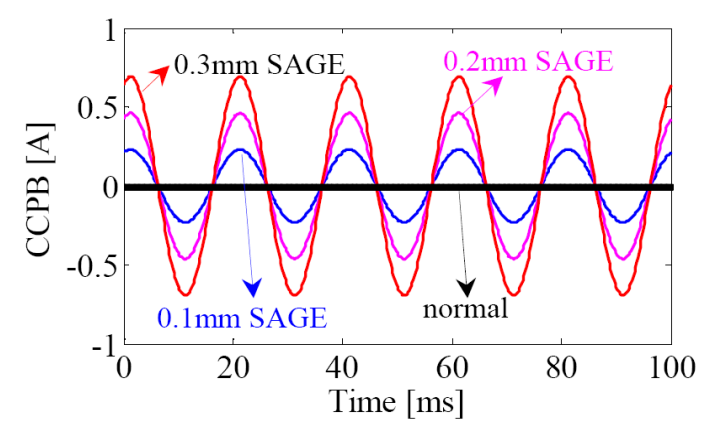

(a)

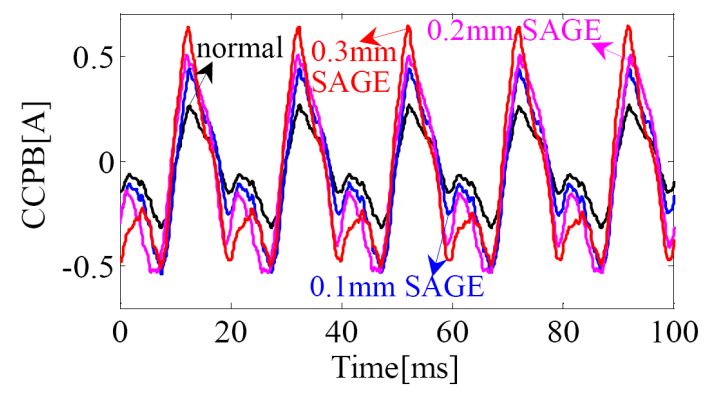

(c)

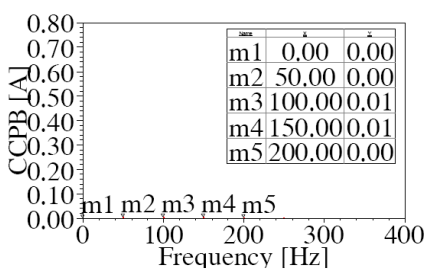

(e)

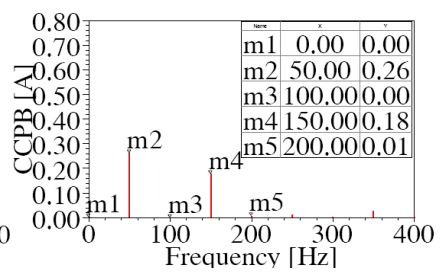

(f)

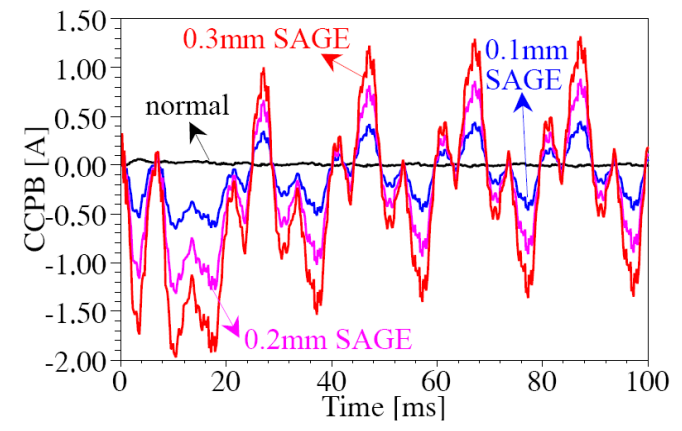

(b)

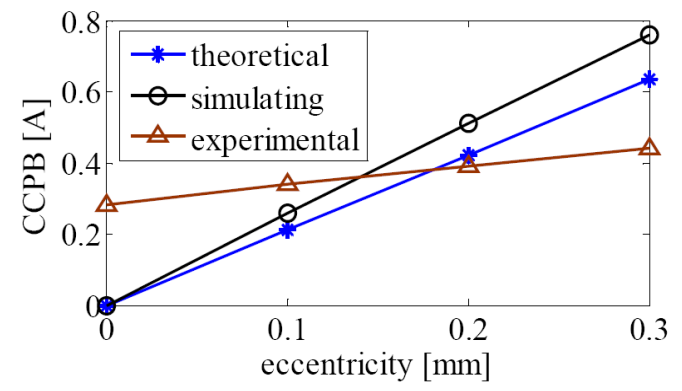

(d)

Fig. 11. CCPB results: (a)-(c) time domain curves of the theoretical, the simulating, and the experimental results; (d) $1^{\text {st }}$ harmonic comparison, and (e)-(h) spectra of CCPB in the case of normal condition, $0.1 \mathrm{~mm}$ SAGE, 0.2mm SAGE, and $0.3 \mathrm{~mm}$ SAGE, respectively

Table 3. United Electromagnetic criterions to monitor and diagnosis the SAGE condition

\begin{tabular}{|c|c|c|c|c|}
\hline \multicolumn{4}{|c|}{ United Electromagnetic characteristics } & \multirow{2}{*}{ SAGE Condition } \\
\hline Magnetic flux density & Stator vibration & Rotor vibration & $\mathrm{CCPB}$ & \\
\hline $\begin{array}{c}\text { Apparent } 1^{\text {st }} \text { harmonic, and } \\
\text { odd harmonics with small } \\
\text { values. Harmonic amplitudes } \\
\text { change little. }\end{array}$ & $\begin{array}{l}2^{\text {nd }} \text { harmonic vibration with } \\
\text { small stable amplitudes }\end{array}$ & $\begin{array}{l}1^{\text {st }} \text { harmonic vibration with } \\
\text { small amplitudes, the } 2^{\text {nd }} \\
\text { harmonic vibration is little } \\
\text { and generally stable }\end{array}$ & $\begin{array}{c}\text { No CCPB or only odd harmonics } \\
\text { with small values, and the } \\
\text { amplitudes change little. }\end{array}$ & $\begin{array}{l}\text { Normally performing, } \\
\text { SAGE is little, within } \\
\text { the permitted extent. }\end{array}$ \\
\hline $\begin{array}{c}1^{\text {st }} \text { harmonic has an apparent } \\
\text { amplitude increment, other } \\
\text { odd harmonics are also } \\
\text { increased }\end{array}$ & $\begin{array}{l}\text { Obvious } 2^{\text {nd }} \text { harmonic } \\
\text { vibration, with a obvious } \\
\text { amplitude increment }\end{array}$ & $\begin{array}{l}\text { Obvious } 2^{\text {nd }} \text { harmonic } \\
\text { vibration, with a obvious } \\
\text { amplitude increment }\end{array}$ & $\begin{array}{c}\text { Obvious } 1^{\text {st }} \text { harmonic CCPB, } \\
\text { with an apparent amplitude rise, } \\
\text { other odd harmonics have also } \\
\text { amplitude increments }\end{array}$ & SAGE exists \\
\hline $\begin{array}{c}1^{\text {st }} \text { harmonic is being } \\
\text { increasing, so are the other odd } \\
\text { harmonics }\end{array}$ & $\begin{array}{l}\text { The } 2^{\text {nd }} \text { harmonic vibration } \\
\text { amplitude is increasing }\end{array}$ & $\begin{array}{l}\text { The } 2^{\text {nd }} \text { harmonic vibration } \\
\text { amplitude is increasing }\end{array}$ & $\begin{array}{l}1^{\text {st }} \text { harmonic is being increasing, } \\
\text { so are the other odd harmonics }\end{array}$ & SAGE is developing \\
\hline
\end{tabular}

that of the stator MPPUA. The mean values and the $2^{\text {nd }}$ harmonic have a greatest increment. The corresponding rise rates from normal condition to $0.1,0.2$, and $0.3 \mathrm{~mm}$ SAGE cases for the mean value $(0 \mathrm{~Hz})$ in $\mathrm{X}$ direction are $6046.9 \%, 12314.3 \%$, and $20294.9 \%$, respectively, while in $\mathrm{Y}$ direction are $433.4 \%, 873.5 \%$, and $1328.7 \%$, respectively. The increment percentages of the $2^{\text {nd }}$ harmonic in $\mathrm{X}$ direction are $8331.8 \%, 17453.3 \%$, and $27628.1 \%$, respectively, while in Y direction are $884.5 \%$, $1975.5 \%$, and $3121.2 \%$, respectively. These data is in accordance with the theoretical analysis.

Objectively, the rotor UMP in normal condition is zero (see Fig. 9 (a) and (b)) and therefore theoretically the rotor should have no vibrations. However, the tested data shows 
that the rotor has vibrations even in normal condition, see Fig. 9 (e). This is mainly caused due to the asymmetry inside the generator and the unbalanced mass distribution of the rotor.

\subsubsection{Influence on $\mathrm{CCPB}$}

The theoretical calculation, together with the simulating and the testing results of CCPB, is shown in Fig. 11. As indicated in Fig. 11 (a)-(c), the theoretical curves are smooth and ideal, while the simulating and the experimental curves have distortions. However, the general growing trends of the three group curves are consistent.

The comparison of the fundamental-frequency CCPB is presented in Fig. 11 (d), where the theoretical and the simulating results are generally in good accordance, while the experimental result deflects from the other two. This is not hard to understand because the practical experiment system has more affected factors such as the asymmetry inside the generator. In theory, when there is no SAGE existing, the electromotive force difference between the two parallel branches is zero (see Fig. 11 (a)). This means there should be no CCPB in normal condition. However, the air-gap of the physical generator is very difficult to be strictly symmetric, which will lead to an original CCPB (see Fig. 11 (c)).

The detailed data of the simulating CCPB harmonics is indicated in Fig. 11 (e)-(h). It shows that in normal condition the $1^{\text {st }}$ harmonic has only a very small value of $0.0043 \mathrm{~A}$, which can be neglected, while in the cases of $0.1 \mathrm{~mm}, 0.2 \mathrm{~mm}$ and $0.3 \mathrm{~mm}$ SAGE, the $1^{\text {st }}$ harmonic amplitude is $0.26 \mathrm{~A}, 0.51 \mathrm{~A}$, and $0.76 \mathrm{~A}$, respectively. Besides the $1^{\text {st }}$ harmonic, the third harmonic also has an obvious increment. This is because that the magnetic flux density has each odd harmonic component, with the $1^{\text {st }}$ and the $3^{\text {rd }}$ harmonics having the largest values. In the theory analysis section, for the sake of convenience, only the $1^{\text {st }}$ harmonic is taken into account while other harmonics are ignored (see Fig. 11 (a)). Generally, the simulating results follow the previous analysis.

However, compare Fig. 11 (c) with (b) it can be found that the simulating CCPB is larger than the experiment one. This may be caused by the following two factors. 1) The simulating condition is ideal and therefore the electromotive force difference will probably have a larger value but meanwhile the resistance between the two branches will be smaller, resulting in a larger CCPB. 2) The simulating CCPB curves include each odd harmonic component, while practically the amplitudes of many higher order harmonics are zero. Consequently, the simulating pass-band waves in the time domain have a larger value. This can be confirmed by comparing Fig. 11 (e)-(h) with (a) and (c). It is indicated that the amplitudes of the simulating $1^{\text {st }}$ harmonics are very close to the theoretical and the experimental ones.

\section{Monitoring Method for SAGE}

On the basis of the theoretical analysis, the simulation study, and the experiment work, a new online monitoring method for SAGE can be developed, and the detailed criterions are shown in Table 3. This method needs to sample the referenced data of the magnetic flux density, the stator vibration, the rotor vibration, and CCPB when the generator is in a good running condition. The judgment of the SAGE condition is based on the amplitude comparison between the real-time data and the referenced data. Practical verifications on the SDF-9 type fault simulating generator have confirmed the effectiveness of this method.

\section{Conclusion}

This paper investigates the united Electromagnetic characteristics of turbo-generator in normal condition and SAGE cases, and a new online monitoring and diagnosis method based on the united characteristics is proposed. According to the results obtained from the theoretical analysis, and the calculation and the experiment studies, primary conclusions can be drawn up as follows.

1) The magnetic flux density in normal condition is mainly composed of odd harmonics, with the $1^{\text {st }}$ harmonic having the max amplitude. The occurrence of SAGE will increase the DC value and the amplitude of each odd harmonic, especially the $1^{\text {st }}$ harmonic.

2) Normally, the stator vibrates at $2 f$, with relatively small amplitudes. However, when SAGE takes place, the $2^{\text {nd }}$ harmonic vibration will be greatly intensified.

3) Theoretically, the rotor should have no vibrations due to the zero value of UMP in normal condition, while practically the rotor vibrates at $f$, with relatively small and stable amplitudes. The appearance of SAGE will bring in apparent $2^{\text {nd }}$ harmonic vibrations to the rotor.

4) There is no CCPB under normal condition in theory, while actually odd harmonics may exist due to the asymmetry inside the generator. When SAGE happens, the odd harmonics of $\mathrm{CCPB}$, especially the $1^{\text {st }}$ harmonic, will be increased.

5) As SAGE increases, the odd harmonics of the magnetic flux density and CCPB will be increased, with the $1^{\text {st }}$ harmonic having the most obvious increment. Meanwhile, the $2^{\text {nd }}$ harmonic vibrations of the stator and the rotor will be also greatly increased. These united electromagnetic characteristics can be applied to monitor and diagnose the SAGE condition.

The proposed work in this paper offers a new thought for the academic study and the practical monitoring on SAGE. However, at the mean time, we also would like to point out that, the practical application of the proposed online monitoring method may face defects due to the current 
transformer installing requirement, which may be not welcomed by the practical operators in the power plants. Further studies will be carried out to overcome this disadvantage.

\section{Acknowledgements}

This work is supported by National Natural Science Foundation of China (51307058), Natural Science Foundation of Hebei Province, China (E2015502013, E2014502052), and Chinese Fundamental Research Funds for the Central Universities (2015ZD27).

\section{References}

[1] Rosenberg, L.T., "Eccentricity, Vibration, and Shaft Currents in Turbine Generators," Power Apparatus and Systems, Part III. Transactions of the American Institute of Electrical Engineers, vol. 74, no. 3, pp. 38-41, Jan. 1955.

[2] Swann, S.A., "Effect of rotor eccentricity on the magnetic field in the air-gap of a non-salient-pole machine," Proceedings of the Institution of Electrical Engineers, vol. 110, no. 5, pp. 903, 915, May 1963.

[3] J. R. Cameron, W. T. Thomson, and A. B. Dow, "Vibration and current monitoring for detecting airgap eccentricity in large induction motors," Proc. Inst. Elect. Eng.-Elect. Power Appl., Vol. 133, No. 3, pp. 155-163, May 1986.

[4] G. Dorrell, W. T. Thomson, and S. Roach, "Analysis of air-gap flux, current and vibration signals as a function of the combination of static and dynamic air-gap eccentricity in 3-phase induction motors," IEEE Trans. Ind. Appl., vol. 33, no. 1, pp. 24-34, Jan./Feb. 1997.

[5] Ebrahimi B. M., Faiz J., Roshtkhari M. J., "Static-, Dynamic-, and Mixed-Eccentricity Fault Diagnoses in Permanent-Magnet Synchronous Motors," IEEE Transactions on Industrial Electronics, Vol. 56, No. 11, pp. 4727-4739, Nov. 2009.

[6] He Yuling, Wan Shuting, Tang Guiji, Xiang Ling, "Eccentric fault identification of a turbo-generator based on stator vibration characteristics," Journal of Vibration and Shock, Vol. 31, No .22, pp. 53-57, 2012.

[7] Wan Shuting, He Yuling, "Investigation on Stator and Rotor Vibration Characteristics of Turbo-generator under Air Gap Eccentricity Fault," Transactions of the Canadian Society for Mechanical Engineering, Vol. 35, No. 2, pp. 161-176, 2011.

[8] Guiji Tang, Yuling He, and Shuting Wan, "Investigation on Stator Vibration Characteristics under Air-Gap Eccentricity and Rotor Short Circuit Composite Faults," Journal of the Brazilian Society of Mechanical Sciences and Engineering, Vol. 36, No. 3, pp. 511-522, 2014.

[9] Stephen D. Umans, A. E. Fitzgerald, Charles Kingsley Jr., "Fitzgerald \& Kingsley's Electric Machinery (Seventh Edition)," McGraw-Hill Science, Engineering, Math, 2013.

[10] Mahmoud, H.; Bianchi, N., "Eccentricity in Synchronous Reluctance Motors - Part I: Analytical and Finite-Element Models," IEEE Transactions on Energy Conversion, vol. 30, no. 2, pp. 745-753, 2015.

[11] C. Di, X. Bao, H. Wang, Q. Lv and Y. He, "Modeling and Analysis of Unbalanced Magnetic Pull in Cage Induction Motors With Curved Dynamic Eccentricity," IEEE Transactions on Magnetics, vol. 51, no. 8 , pp. 1-7, 2015.

[12] Iman Tabatabaei, Jawad Faiz, H. Lesani, M. T. Nabavi-Razavi, "Modeling and Simulation of a Salient-Pole Synchronous Generator with Dynamic Eccentricity Using Modified Winding Function Theory," IEEE Transactions on Magnetics, Vol.40, No. 3, pp. 1550-1555, 2004.

[13] Shakouhi, M.; Mohamadian, M.; Afjei, E., "FaultTolerant Control of Brushless DC Motors Under Static Rotor Eccentricity," IEEE Transactions on Industrial Electronics, vol. 62, no. 3, pp. 1400-1409, March 2015.

[14] Bruzzese C., "Diagnosis of Eccentric Rotor in Synchronous Machines by Analysis of Split-Phase Currents - Part I : Theoretical Analysis," IEEE Transactions on Industrial Electronics, Vol. 61, No. 8, pp. 4193-4205, Aug. 2014.

[15] Mirimani, S.M.; Vahedi, A.; Marignetti, F.; Di Stefano, R., "An Online Method for Static Eccentricity Fault Detection in Axial Flux Machines," IEEE Transactions on Industrial Electronics, vol. 62, no. 3, pp. 1931-1942, March 2015.

[16] Jean-Jacques Simond, Mai Tu Xuan, Roland Wetter, "An Innovative Inductive Air-Gap Monitoring for Large Low Speed Hydro-Generators," Proceedings of the 2008 International Conference on Electrical Machines, pp.1-5, 2008.

[17] Bruzzese C., Joksimovic G., "Harmonic Signatures of Static Eccentricities in the Stator Voltages and in the Rotor Current of No-Load Salient-Pole Synchronous Generators," IEEE Transactions on Industrial Electronics, Vol. 58, No. 5, pp. 1606-1624, May 2011.

[18] Bruzzese C., "Diagnosis of Eccentric Rotor in Synchronous Machines by Analysis of Split-Phase Currents - Part II: Experimental Analysis," IEEE Transactions on Industrial Electronics, Vol. 61, No. 8, pp. 4206-4216, Aug. 2014.

[19] Doorsamy W., Abdallh A.A.-E., Cronje W.A., Dupre L., "An Experimental Design for Static Eccentricity Detection in Synchronous Machines Using a Cramér - Rao Lower Bound Technique," IEEE Trans-actions on Energy Conversion, Vol. 30, No. 1, pp. 254-261, 
March 2015.

[20] Gui-Ji Tang, Yu-Ling He, Shu-Ting Wan, and Ling Xiang, "Investigation on Stator Vibration Characteristics Under Air-Gap Eccentricity And Rotor Short Circuit Composite Faults," Journal of the Brazilian Society of Mechanical Sciences and Engineering, Vol. 36, No. 3, pp. 511-522, 2014.

[21] Yuling He, Guiji Tang, Shuting Wan, Yucai Wu, "Effect of the Static Air-Gap Eccentricity \& Stator Inter-Turn Short Circuit Composite Fault on the Generator Circulating Current Characteristics," International Review of Electrical Engineering, Vol. 5, No. 5, pp. 5442-5450, 2012.

[22] Shuting Wan, Yuling He, Guiji Tang, Yonggang Li, "Investigation on Stator Circulating Current characteristics under Air Gap Eccentricity and Rotor Short Circuit Composite Faults," Electric Power Components and Systems, Vol. 38, No. 8, pp. 900-917, 2010.

[23] L. T. Rosenberg, "Abnormal Vibration Problems in Large Turbine-Driven Generators and Their Solutions," IEEE Transactions on Power Apparatus and Systems, vol. PAS-101, no. 10, pp. 4131-4135, 1982.

[24] H. C. Dirani et al., "Free vibration analysis of a large hydroelectric generator and computation of radial electromagnetic exciting forces," 2015 IEEE International Electric Machines \& Drives Conference (IEMDC), pp. 328-334, 2015.

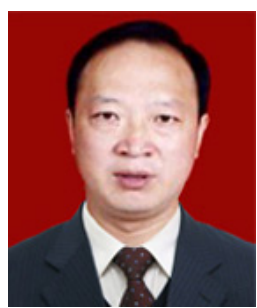

Gui-Ji Tang He received the B.S. degree in Mechanical Design And Manufacturing, the M.S. degree in Power Plant Engineering, and the Ph.D. degree in Thermal Engineering, in 1983, 1991, and 1999, respectively, all from North China Electric Power University, China. His main research interests include testing technology, vibration monitoring and control, fault diagnosis on rotary machine.

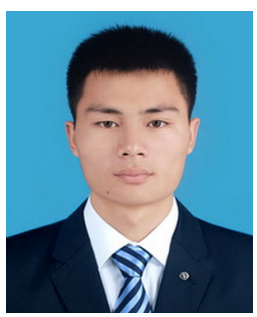

Meng-Qiang Ke He received the B.S. degree in Mechanical Engineering in 2013, and the M.S. degree in Mechatronics Engineering in 2016, both from North China Electric Power University, China. His main research interest is fault diagnosis on rotary machine.

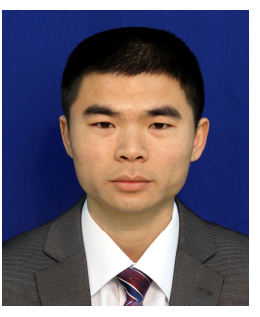

Yu-Ling $\mathrm{He} \mathrm{He}$ received two B.S. degrees respectively in Mechanical Engineering and Electrical Engineering in 2007, the M.S. degree in Mechatronics Engineering in 2009, and the Ph.D. degree in Power Machinery \& Engineering in 2012, all from North China Electric Power University, China His main research interest is condition monitoring and fault diagnosis on large power equipments.

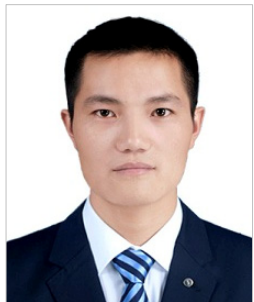

Fa-Lin Wang He received the B.S. degree in Mechanical Engineering in 2013, and the M.S. degree in Mechatronics Engineering in 2016, both from North China Electric Power University, China. His main research interest is fault diagnosis on rotary machine. 